\section{P185 AN EVALUATIVE STUDY OF BREATH SOUNDS TEACHING}

doi:10.1136/thoraxjnl-2011-201054c.185

C F Ramsay. Norfolk \& Norwich University Hospital NHS Foundation Trust, Norwich, UK

Introduction Recorded breath sounds on CD and electronic stethoscopes that can record and playback sounds open up new possibilities for teaching and analysing factors contributing to breath sounds variability.

Aims Assessment of the intra and inter tutor variability in describing recorded breath sounds and of medical students learning preferences for breath sounds teaching.

Methods Seven tutors (four consultants and three specialist registrars in respiratory medicine) were played twenty-two recorded breath sounds. Tutors were asked to "write down exactly how you would teach a student to describe the breath sounds". Within the twenty-two recordings five identical breath sounds were played twice, one sound was played at two different volumes and two patients were each played at two differing expiratory efforts. A feedback session with the tutors was subsequently held. A separate student evaluation comprised an anonymous questionnaire at the end of their clinical attachment. Twenty-one students were asked to choose their two preferred methods of learning chest auscultation. Results All tutors gave a précis of the most important feature(s) rather than structured responses. There was a very large degree of inter-observer variability, which was difficult to quantify partly due to the lack of structured descriptions. Recordings at different expiratory efforts resulted in different descriptions from all tutors. When listening to identical pairs of recorded breath sounds $29 \%$ of the tutors' descriptions were concordant, $42 \%$ partly concordant and $29 \%$ different. Abstract P185 figure 1 shows the intra-tutor variability and students' preferred learning methods. For the vast majority of students, experience examining a patient with a tutor or with a tutor using a recording stethoscope was the preferred learning method. Twelve of the twenty-one students had experience of being taught with a recording stethoscope and ten of these students put it down as one of their two preferences.

Conclusions There was significant intra-tutor variability in describing breath sounds comparable with previous studies in this area. A structured methodology would assist in assessing inter tutor

\section{Intra-observer variability}

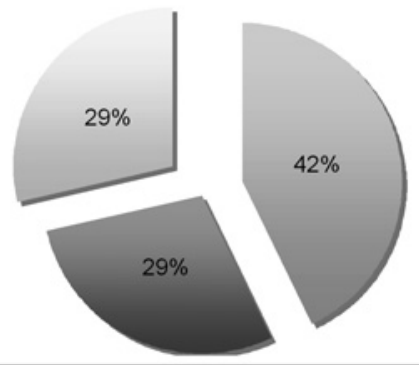

Identical description/meaning

Partially consistent description

Different description

\section{Student's learning preferences}

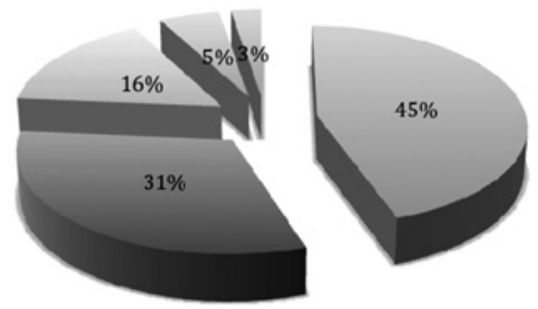

= Patient + Tutor

$=$ Patient +'Tutor + electronic stethescope

$\mathrm{CD}+$ Tutor

$=\mathrm{CD}$

Internet concordance. Both students and tutors preferred teaching with patients to recordings. A recording stethoscope was perceived to be a useful adjunct to teaching by students.

\section{P186 THE RELIABILITY OF THE RESPIRATORY PHYSICAL EXAMINATION}

doi:10.1136/thoraxinl-2011-201054c.186

${ }^{1} \mathrm{M}$ Newnham, ${ }^{1} \mathrm{E}$ Jones, ${ }^{2} \mathrm{D}$ Wall, ${ }^{1} \mathrm{R}$ Mukherjee. 'Birmingham Heartlands Hospital, Birmingham, UK; ${ }^{2}$ University of Birmingham, Birmingham, UK

Background We often teach and assess medical students performing the respiratory examination in a traditional way, rather than based on evidence. An essential component of the respiratory clinical examination is that it is precise. The reliability of the examination is a fundamental element of this precision. There needs to be agreement between physicians that a clinical sign can be elicited independently in the same patient when it is present. When learning about the respiratory examination, medical students should have knowledge of the reliability of the different elements.

Aims To establish medical students' knowledge of the reliability of different elements of the respiratory examination.

Methods A cross sectional questionnaire survey of clinical medical students (years 3-5) was undertaken. The questionnaire assessed the reliability of tactile vocal fremitus, tracheal position, auscultation of wheeze, whispering pectoriloquy, auscultation of crackles and chest expansion using a five point Likert scale. Demographic data were also collected. The results of the perceived reliability of different elements of the respiratory examination was compared with Cohen's $\kappa$ coefficient values; a statistical measure of interobserver reliability.

Results Of 104 questionnaires completed, 33\% were male, 36\% attached to respiratory firm, 11\% graduate entry. Crackles, wheeze and percussion note are all regarded as reliable to very reliable signs by students. Perceived reliability of whispering pectoriloquy decreased as students become more experienced $(p=0.003)$. There was no relationship between perceived reliability and graduate entry, previous respiratory attachment or gender. Factor analysis identified that tactile vocal fremitus and whispering pectoriloquy were grouped together separately from the other respiratory signs. Linear regression showed good correlation between students answers and actual $\kappa$ values of reliability $(r=0.722)$.

Conclusions Students have a good intuition of the reliability of elements of the respiratory examination. For example, as experience increases, they correctly perceive whispering pectoriloquy as a less reliable sign. Reliability of elements of the respiratory examination needs consideration when teaching and assessing students.

\section{P187 DOES GREATER PHYSICIAN INVOLVEMENT WITH INTERVENTIONAL PROCEDURE CODING IMPROVE CODING OUTCOME?}

doi:10.1136/thoraxjn|-2011-201054c.187

A R L Medford, A Pillai. North Bristol Lung Centre, Bristol, UK

Background The Royal College of Physicians of London Health Informatics Unit has developed the Professional Record Keeping Standards. Trusts have a financial incentive to code activity accurately under Payment by Results. Coding inaccuracy is well described by the Audit Commission varying from $0.3 \%$ to $52 \%$ across Acute Trusts in England, with the potential for gross financial disparity, with particular inaccuracy in interventional specialties. ${ }^{1}$ We have previously noted a $14.6 \%$ coding inaccuracy rate for endobronchial ultrasound-guided transbronchial needle aspiration (EBUSTBNA). ${ }^{2}$ Given that the specific EBUS-TBNA tariff is approximately six times the conventional bronchoscopy tariff, EBUS-TBNA is a good model to illustrate the potential financial effects. 
Hypothesis Greater physician involvement with a prospective coding cross-checking system would improve coding outcome for EBUS-TBNA and financial disparity.

Methods From November 2010 to June 2011, 52 consecutive patients underwent EBUS-TBNA in a UK teaching hospital. After every procedure, anonymised patient details were emailed securely to the Trust Coding Lead. Every month, the Trust Informatics Lead would email the final coding outcomes and tariffs for all the EBUSTBNA patients. These were cross-checked against a prospective anonymised procedure database. Primary outcome was coding accuracy. Data were compared to a previous EBUS-TBNA coding study ${ }^{2}$ as a control (no coding intervention) using contingency table analysis with Fishers Exact Test and a $p$ value of $<0.05$ was deemed significant (GraphPad Prism 5 software). Differences in financial loss were calculated using a tariff of $£ 504$ for conventional bronchoscopy and £3404 for EBUS-TBNA (E63.2+T87.4).

Results All 52 patients were coded correctly with no financial loss. From the previous study of 52 patients, 8 (14.4\%) were coded incorrectly which was significant (OR 20.1, 1.1-357.5, $\mathrm{p}=0.006$, Fishers Exact). Financial loss to the NHS Trust was calculated as $£ 23200$, projected to $£ 40000$ per year.

Conclusion Greater physician engagement with coders improves coding outcomes. This is of particular importance in interventional specialties where the potential for financial loss is of a higher magnitude. A simple prospective cross-checking system can achieve better outcomes with no extra cost and minimal effort.

\section{REFERENCES}

1. Audit Commission. PbR Data Assurance Framework 2007/08: findings from the first year of the national clinical coding audit programme. http://www.audit-commission. gov.uk/Products/NATIONAL-REPORT /CD8608E5-A7D9-4a5a-BOF3-C161B76DE630/ PbRreport.pdf (accessed 26 Aug 2009).

2. Medford AR, Agrawal S, Free CM, et al. A performance and theoretical cost analysis of endobronchial ultrasound-guided transbronchial needle aspiration in a UK tertiary respiratory centre. OJM 2009;102:859-64.

\section{P188 IMPACT OF WARD BASED CHEST ULTRASOUND ON THE RADIOLOGY DEPARTMENT}

doi:10.1136/thoraxjnl-2011-201054c.188

H Lockman, N J Withers. Royal Devon and Exter Hospital, Exeter, Devon

Introduction The ability for chest physicians to perform chest ultrasound is on the increase since the NPSA report concerning chest drain insertion and the BTS Pleural guidelines 2010. Our respiratory department received a portable ultrasound device (Sonosite 180 Plus) in April 2010 and by August 2010 we had 3 physicians who have achieved level 1 thoracic ultrasound skill (1 Chest Consultant, 2 Specialist Registrars-1 Respiratory, 1 Acute Medicine). We were keen to see what kind impact this has made on the chest ultrasound requests on the radiology department.

Methods Data collected comparing 2 periods. Dataset 1: Nov 2009-Jan 2010 and Dataset 2: Nov 2010-Jan 2011. Information was gathered via the Webpacs system (GE Medical System: Centricity ${ }^{\circledR}$ Enterprise Web) and the CRIS-Clinical Radiology Information System (Healthcare software system). Only adult (=16 years) inpatient request were included.

Results

\begin{tabular}{ll}
\hline Dataset 1: Nov 2009-Jan 2010 & Dataset 2: Nov 2010-Jan 2011 \\
\hline $\mathrm{n}=81$ & $\mathrm{n}=45$ \\
$55(68 \%)$ scan done on same day of & $32(71 \%)$ scan done on same day \\
receiving request & of receiving requests \\
All scans done within 6 days & All scans done within 3 days \\
Imaged saved $62(77 \%)$ & Images saved $35(78 \%)$ \\
\hline
\end{tabular}

Summary Having physicians with skills to perform chest ultrasound by the bedside has reduced the burden on the radiology department and the response times to the scan all the patients has halved from 6 to 3 days. We hope this service can be further improved with more physicians attaining this skill.

\section{P189 EVALUATION OF THE ROLE OF CARDIO-PULMONARY EXERCISE TESTING IN THE DIAGNOSIS OF UNEXPLAINED BREATHLESSNESS}

doi:10.1136/thoraxjnl-2011-201054c.189

J E R Thing, B Mukherjee, K Murphy, H Tighe, L Howard. Hammersmith Hospital, London, UK

Introduction and Objectives Cardio-Pulmonary Exercise Testing (CPET) provides a non-invasive measurement of cardiac and pulmonary function. CPET offers a unique assessment tool for the investigation of patients with unexplained dyspnoea (UD). These individuals often undergo exhaustive, expensive and invasive assessment without definitive diagnosis. CPET can provide valuable diagnostic information and helps to focus further assessment of the dyspnoeic patient. The aim of this retrospective cohort study was to evaluate the outcome of CPET in patients with UD and to determine how clinically useful the test is at influencing further management. Methods CPET data were collected between February 2008 and February 2011 for patients with UD and analysed retrospectively. Data included demographics, pre-CPET investigation results, the CPET report and post-CPET clinic letters. This information was accessed via hospital reporting systems as well as a local CPET database and patient notes.

Results Patient demographics and pre-CPET investigation data are shown in Abstract P189 table 1. Patients were assigned diagnoses based on test reports. A total of $96(64 \%)$ patient letters were obtained to

Abstract P189 Table 1 Table demonstrating -A: Patient demographics, B: Investigation performed in 6 months prior to CPET (unless stated), C: Post CPET diagnosis

\begin{tabular}{|c|c|c|c|}
\hline \multicolumn{2}{|l|}{ Pre-test } & \multicolumn{2}{|l|}{ Post-test } \\
\hline A & & C & \\
\hline Demographics & Mean (range) & Diagnosis & $\begin{array}{l}\text { No. with specific } \\
\text { diagnoses }(\%)\end{array}$ \\
\hline BMI & $\begin{array}{l}27.7 \mathrm{~kg} / \mathrm{m}^{2} \\
(17.6-43.8)\end{array}$ & Normal & $41(27)$ \\
\hline Age & 53.5 yrs $(17-80)$ & Deconditioning & $26(17)$ \\
\hline Sex distribution & $\begin{array}{l}\text { Female } 70 \% \\
\text { Male } 30 \%\end{array}$ & $\begin{array}{l}\text { Pulmonary } \\
\text { vascular disease }\end{array}$ & $24(16)$ \\
\hline B & & $\begin{array}{l}\text { Dysfunctional } \\
\text { breathing }\end{array}$ & $23(15)$ \\
\hline & & Cardiac pump failure & $18(12)$ \\
\hline Investigation & $\%$ Performed & $\begin{array}{l}\text { Chronotropic } \\
\text { Insufficiency }\end{array}$ & $11(7)$ \\
\hline Lung function & 91 & Heart Failure & $10(7)$ \\
\hline Any blood test (6 months) & 67 & None & $10(7)$ \\
\hline Chest radiograph & 67 & $\begin{array}{l}\text { Ischaemic } \\
\text { heart disease }\end{array}$ & $9(6)$ \\
\hline Echocardioram & 45 & Myopathy & $9(6)$ \\
\hline CT scan & 27 & Drugs & $7(5)$ \\
\hline $\mathrm{V} / 0$ scan & 23 & Raised BMI & $7(5)$ \\
\hline Coronary angiogram & 15 & $\begin{array}{l}\text { Obstructive } \\
\text { lung disease }\end{array}$ & $5(3)$ \\
\hline Cardiac treadmill test & 7 & $\begin{array}{l}\text { Restrictive } \\
\text { lung disease }\end{array}$ & $5(3)$ \\
\hline 6-min walk test & 4 & Cardiomyopathy & $1(1)$ \\
\hline Cardiac MRI & 3 & Metabolic causes & $1(1)$ \\
\hline Pleural biopsy & 1 & Rhythm abnormality & $1(1)$ \\
\hline
\end{tabular}

